\title{
Jack of All Trades or Master of One? Product Differentiation and Compensatory Reasoning in Consumer Choice
}

\author{
ALEXANDER CHERNEV*
}

\begin{abstract}
This research examines consumer reactions to two common positioning strategies: a specialized-positioning strategy in which an option is described by a single feature, and an all-in-one strategy in which an option is described by a combination of features. The empirical data reported in this article demonstrate that a product specializing on a single attribute is perceived to be superior on that attribute relative to an all-in-one option, even when this attribute is exactly the same for both options. It is further shown that the observed devaluation of the all-in-one option can be mitigated by introducing another attribute on which the all-in-one option is inferior to the specialized option.
\end{abstract}

$\mathrm{W}$ hen designing their products, companies often choose one of two positioning strategies: a narrower, specialized positioning in which products are described by a single attribute and a broader, all-in-one positioning in which products are described by a combination of attributes. To illustrate, Era is positioned by Procter and Gamble as the detergent with "powerful stain removal," Cheer promises to "help protect against fading," Gain offers "great cleaning power," and, finally, Tide combines all of the above features. Combining these positioning strategies raises the question of how consumers evaluate specialized options in the presence of an all-in-one option, and vice versa.

From a conceptual standpoint, combining specialized and all-in-one options raises several issues: (1) whether and how the perceived performance of the attributes differentiating an all-in-one option would change in the presence of options specialized on each of these attributes (e.g., the change in the perceived stain-removal and fading-prevention performance of Tide in the presence of Era and Cheer); (2) whether and how the perceived performance of the differentiating attribute of a specialized option would change in the presence of an all-in-one option (e.g., the change in the perceived stain-removal performance of Era and the fading-prevention

*Alexander Chernev is associate professor of marketing, Kellogg School of Management, Northwestern University, Evanston, IL 60208 (ach@ northwestern.edu). The author thanks Gregory Carpenter, Pierre Chandon, Ryan Hamilton, the editor, associate editor, and the three anonymous reviewers for their constructive comments. This research has benefited from seminars at the University of Pennsylvania and Cornell University.

Dawn Iacobucci served as editor and Durairaj Maheswaran served as associate editor for this article.

Electronically published January 22, 2007 performance of Cheer in the presence of Tide); and (3) whether and how the perceived performance of nondifferentiating attributes of a specialized option would change in the presence of an all-in-one option (e.g., the change in the perceived fading-prevention performance of Era and the stain-removal performance of Cheer in the presence of Tide). Despite their conceptual importance and practical relevance, these issues have not been explicitly addressed in the marketing literature.

This research examines consumer reactions to specialized and all-in-one product positioning strategies. In particular, it is argued that when a specialized option is compared with an all-in-one option, the perceived performance of the specialized option on its focal attribute is enhanced relative to when it is considered in isolation. In contrast, the perceived performance of the all-in-one option is likely to decrease when it is compared with a specialized product relative to when it is considered in isolation. The logic for this prediction and the empirical analyses are discussed in more detail in the following sections.

\section{COMPENSATORY REASONING IN CONSUMER CHOICE}

The concept of compensation has been used in psychology, decision making, and marketing in different contexts. In psychology literature, the term "compensation" has been used to describe a psychological mechanism by which an individual attempts to make up for some personal deficiency by developing or stressing another ability (e.g., Adler 1924). In decision research, "compensation" has been used in reference to the nature of the decision processes underlying an individual's choice strategies, particularly involving the 
ability of an option's strength on one attribute to make up for a deficiency on another (Johnson and Meyer 1984; Payne, Bettman, and Johnson 1993). In this context, compensatory decision strategies, represented by multiattribute utility models (Keeney and Raiffa 1976), imply that an option's strong performance on one attribute can compensate for poor performance on another, whereas in noncompensatory strategies, such as elimination by aspects (Tversky 1972), a good value on one attribute cannot make up for a poor value on another.

Most recently, the notion of compensation has been advanced in a somewhat different context: as a specific inference-making mechanism based on consumers' intuitions of market efficiency (Chernev and Carpenter 2001). In this context, market efficiency reflects the belief that offerings are priced at value parity, such that the benefit-cost tradeoffs are constant across options; as a result, higher priced products are also of better quality, and vice versa. To illustrate, a consumer considering two equally priced alternatives might infer that the option superior on the observed attributes is likely to be inferior on some of the unobservable attributes. Thus, the concept of market efficiency reflects the notion that firms behave rationally, resulting in offerings that are value equivalent. Compensatory inferences derived from consumers' market efficiency beliefs aim to resolve a salient incongruity between the intuitively expected and the observed relationships among options in a given choice set, whereby extreme values on one dimension are associated with inferior performance on another.

Conceptually, compensatory inferences can be linked to consumers' covariation beliefs, which reflect their intuitions about the degree of relationship between two or more factors. Two types of covariation beliefs can be identified: attribute-specific covariation and context-dependent covariation. Most of the extant research has focused on attribute-specific covariation that is confined to pairs of particular factors such as price and quality (Baumgartner 1995; Bettman, John, and Scott 1986; Raghubir and Corfman 1999; Shiv, Carmon, and Ariely 2005), brand name and quality (Allison and Uhl 1964; Janiszewski and Van Osselaer 2000; Rao and Monroe 1989; Wernerfelt 1988), and reliability and warranty (Dick, Chakravarti, and Biehal 1990). To illustrate, consumers might believe that higher quality products are also more expensive (Lichtenstein and Burton 1989) and that more reliable products are likely to offer a longer warranty (Broniarczyk and Alba 1994).

Unlike attribute-based covariation, in which an option's performance on a particular attribute is inferred from its performance on other attributes, in the case of context-based covariation an option's values are derived from the decision context defined by the other alternatives in the set. Examples of such context-based covariation are given by prior research on preference formation, documenting that consumer inferences of product performance are derived from the characteristics of the other alternatives in the set (Prelec, Wernerfelt, and Zettelmeyer 1997; Wernerfelt 1995). In the same vein, prior research has documented that consumer response to marketing programs and promotional offers is a function of the degree to which these activities fit the preferences of target customers better than of the typical customer in the population (Kivetz and Simonson 2003).

Building on prior findings, this research extends the notion of compensatory reasoning beyond attribute-specific covariation to a scenario in which inferences are drawn from the decision context defined by the other alternatives in the set, rather than from this option's performance on a particular attribute. These context-based compensatory inferences stem from a consumer's belief that options in a given choice set are balanced in a way that advantages on one dimension are compensated for by disadvantages on another, even in the absence of prior attribute-specific covariation beliefs. Thus, an option that excels on a particular attribute can be inferred to be inferior on some of the other attributes even in the absence of an inherent covariation among its attributes (e.g., static prevention and stain removing in a laundry detergent).

In this research, the decision strategy reflecting individuals' belief that alternatives in a given choice set are balanced in their overall performance is referred to as the "zerosum heuristic." The term "zero-sum heuristic" is derived from the zero-sum-game assumption in game theory, which implies that the wins and losses in a game will add up to zero for each set of strategies chosen (Von Neumann and Morgenstern 1953). Simply put, a zero-sum game implies that one player's winnings should equal the other player's losses. The concept of zero-sum heuristic advanced in this article is conceptually similar to that of a zero-sum game in that it implies a closed system in which all options are balanced; thus, for each of the options, the advantages on one attribute must be compensated for by disadvantages on another. Thus, the zero-sum heuristic is not contingent on prior covariation beliefs and, instead, is a function of the dispersion of attribute values across choice alternatives. In this context, when consumers who expect options in a given choice set to be comparable in terms of their overall performance are presented with a choice set in which the allin-one option appears to dominate the others, they are likely to draw compensatory inferences devaluing the apparently more attractive all-in-one option.

The zero-sum heuristic can be related to the notion of trade-off consistency in choice (Simonson and Tversky 1992). The trade-off consistency of a given choice set is usually characterized by the rate of exchange between attributes, so that in sets with a constant rate of exchange between attributes the advantages and disadvantages of each option are balanced. In this context, the zero-sum heuristic implies that when evaluating sets comprising options with varying rates of exchange between attributes, consumers are likely to interpret ambiguous attribute values in a way that decreases the observed trade-off contrasts and equates the rate of exchange across attributes.

This research argues that when evaluating sets comprising specialized and all-in-one options, consumer reasoning is often guided by the zero-sum heuristic, which predicts that 
the sum of advantages and disadvantages is constant across the choice options. In this context, it is argued that consumers are likely to interpret the values of the choice alternatives in a way that equates the overall performance of the all-in-one and the specialized options, leading to a compensatory devaluation of the perceived performance of the all-in-one option and enhancement of the perceived performance of the specialized options. This idea is further articulated in a series of research hypotheses in the following section.

\section{RESEARCH HYPOTHESES}

Consider a set of three alternatives, each described on two attributes as follows: option $\mathrm{A}$ is differentiated by attribute 1 , option $\mathrm{B}$ is differentiated by attribute 2 , and option $\mathrm{C}$ is differentiated by both attributes. To illustrate, consider three shaving creams, one emphasizing its moisturizing effect, the second one promoting its skin-protection effectiveness, and the third one claiming to be effective in both skin moisturizing and skin protection. In the absence of compensatory inferences, consumers are likely to view option $\mathrm{C}$ as superior on both attributes (i.e., $c_{1}>b_{1}$ and $c_{2}>$ $a_{2}$ ), as illustrated in figure $1 A$.

The use of the zero-sum heuristic, however, is likely to lead to compensatory inferences that balance the overall attractiveness of options $\mathrm{A}, \mathrm{B}$, and $\mathrm{C}$, making these options trade-off equivalent. In particular, compensatory reasoning is likely to lead to a devaluation of the all-in-one option $\mathrm{C}$ $(\Delta \mathrm{C}$ in fig. $1 B$ ) and a polarization of attribute values of the specialized options $\mathrm{A}$ and $\mathrm{B}(\Delta \mathrm{A}$ and $\Delta \mathrm{B})$. In this context, compensatory inferences can be represented as having a threefold effect. First, the all-in-one option is likely to be devalued, such that the perceived performance of the attributes differentiating an all-in-one option will decrease in the presence of options specialized on these attributes (compensatory devaluation effect denoted by $\Delta \mathrm{c}_{1}$ and $\Delta \mathrm{c}_{2}$ in fig. $1 B)$.

In addition to discounting the performance of the all-inone option $\mathrm{C}$, consumers might also draw inferences about the specialized options $A$ and $B$, such that the perceived performance of the attributes of a specialized option will become more polarized in the presence of an all-in-one option. In particular, the perceived performance of the differentiating attribute of a specialized option will increase in the presence of an all-in-one option (compensatory enhancement effect denoted by $\Delta \mathrm{a}_{1}$ and $\Delta \mathrm{b}_{2}$ in fig. $1 B$ ). At the same time, consumers might also discount the performance of specialized options A and B on their secondary attributes in the presence of an all-in-one option, leading to a downshift in their perceived performance (compensatory devaluation effect denoted by $\Delta \mathrm{a}_{2}$ and $\Delta \mathrm{b}_{1}$ in fig. $1 B$ ).

An important assumption of the zero-sum heuristic is that the choice problem is viewed as fully identified, such that the number of attributes used to define choice alternatives is constant and all attribute values are readily available. This assumption raises the question of how the presence of attributes on which options' performance is not readily observable influences compensatory reasoning. Generally speaking, there are two possibilities. First, consumers might infer that all options have equal values on the unobservable attribute-a scenario that should not influence consumers' use of compensatory reasoning and their reliance on the zero-sum heuristic. The second possibility is that consumers infer that options vary in their performance on the unobservable attribute. In this case, the strength of the zero-sum heuristic is likely to be a function of the pattern of these inferences: it should be stronger when the inferred values are consistent with the readily available dispersion of attribute values and should be weaker (or even disappear) when the inferred attribute values are inconsistent with the dispersion of the values of the readily available attributes.

To illustrate, consider the earlier scenario involving three shaving creams, one emphasizing the moisturizing effect (option A), the second promoting skin-protection effectiveness (option B), and the third claiming to be effective for both skin moisturizing and skin protection (option $\mathrm{C}$ ). Now imagine that an additional attribute (e.g., price, skin conditioning) on which the options' performance is unobservable is part of consumers' evaluation of these options. In this context, it can be argued that the options' performance on the two differentiating attributes (moisturizing and protection) is likely to be a function of their perceived performance on the attribute on which the options' performance is unobservable. In particular, consumers who perceive the all-in-one option $\mathrm{C}$ to be inferior on the unobservable attribute will be less likely to infer a compensatory relationship between the options' values on featured attributes than consumers who perceive option $\mathrm{C}$ to dominate the others on the unobservable attribute.

Overall, this research posits that when evaluating choice sets comprising both all-in-one and specialized alternatives, consumers are likely to adopt a zero-sum heuristic, which equates the overall attractiveness of choice alternatives and evaluates the available information in a compensatory fashion. In particular, two types of compensatory effects can be identified: compensatory devaluation, which lowers the perceived performance of the all-in-one option, and compensatory polarization, which enhances the perceived performance of the specialized option on the differentiating attribute, while detracting from its performance on the secondary attribute. It is further proposed that the strength of the compensatory inferences across the attributes differentiating choice alternatives is a function of the presence of salient attributes on which options' performance is not readily observable. Thus, in the presence of a salient attribute on which options' values are unobservable, compensatory inferences are predicted to be less pronounced than in the case when options' values on all salient attributes are readily observable. Furthermore, when consumers are explicitly asked to make inferences about options' performance on unobservable attributes, compensatory effects are predicted to be less pronounced when the inferred performance is inconsistent with the readily available attribute information. These predictions are tested in the following experiment. 
FIGURE 1

COMPENSATORY ENHANCEMENT AND DEVALUATION EFFECTS IN CHOICE

\section{A. Product Evaluations in the Absence of Compensatory Inferences}

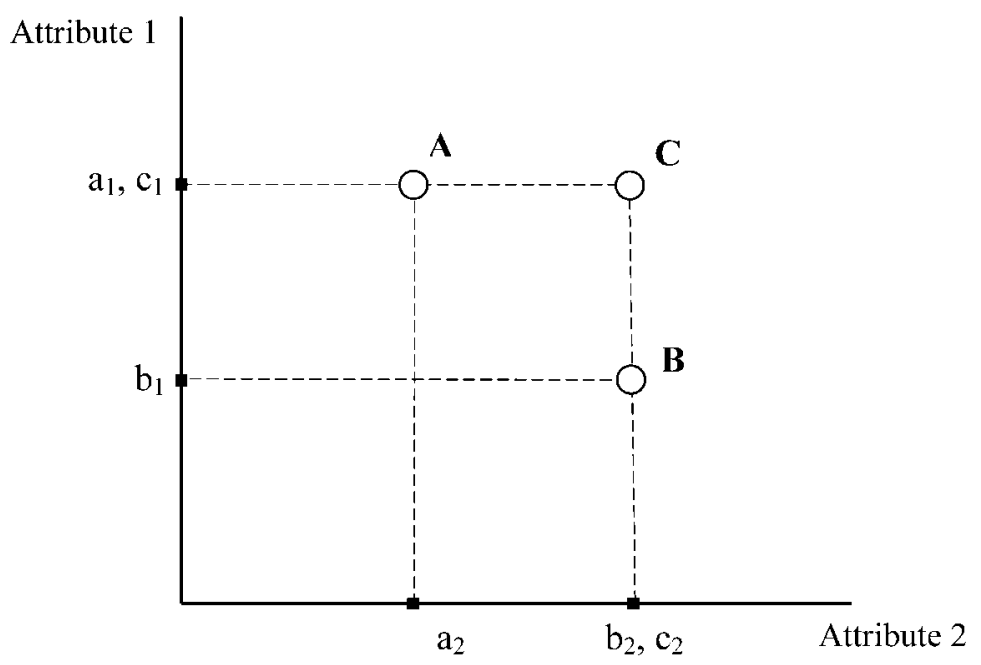

\section{B. Compensatory Enhancement and Devaluation Effects in Choice}

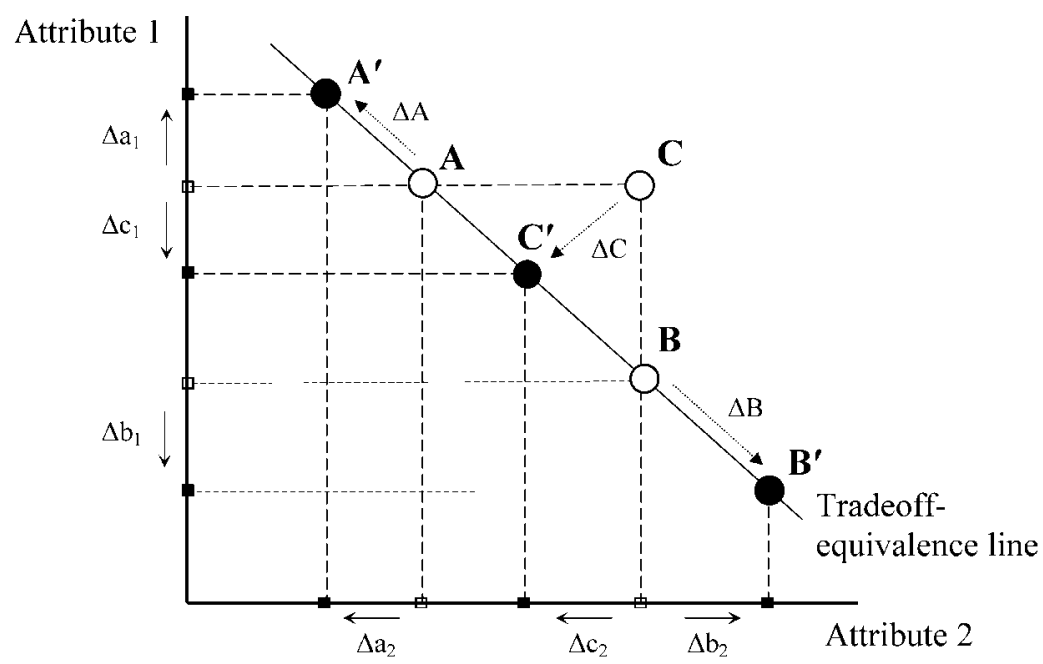

NotE.-A and B are the specialized options, and $C$ is the all-in-one option. $A^{\prime}, B^{\prime}$, and $C^{\prime}$ reflect the perceived performance of options $A$, B, and $C$ in the presence of compensatory inferences. $\Delta a_{1}$ and $\Delta b_{2}$ depict compensatory enhancement, whereby the value of options $A$ and $B$ is enhanced by compensatory inferences. In contrast, $\Delta \mathrm{a}_{2}, \Delta \mathrm{b}_{1}, \Delta \mathrm{c}_{1}$, and $\Delta \mathrm{c}_{2}$ depict compensatory devaluation, whereby attribute values of options $\mathrm{A}, \mathrm{B}$, and $\mathrm{C}$ are decreased by compensatory inferences.

\section{EXPERIMENT 1}

The goal of this experiment was to empirically examine how attribute performance of an all-in-one option is influenced by the presence of specialized options, and vice versa. The specifics of the experimental stimuli and research design are presented in more detail in the following sections.

\section{Method}

The respondents, 227 Northwestern University students, were recruited to participate in a study on consumer decision making and were informed that the choice task involved making hypothetical purchase decisions. Five product categories were used as stimuli: laundry detergent, toothpaste, 
shaving cream, cold relief medicine, and vitamin supplements. Similar categories have been successfully used in prior research (Carpenter and Nakamoto 1989; Simonson 1989). Choice sets consisted of either two or three options, each described by either one attribute (in case of specialized options) or two attributes (in case of all-in-one options) as shown in the appendix, table A1. For all product categories, options A and B were described by a single attribute (e.g., prevents cavities), and option $\mathrm{C}$ was described by a combination of features describing options A and B (e.g., prevents cavities and whitens teeth).

Choice alternatives were organized into four scenarios: a trinary set $\mathrm{ABC}$ and three binary sets $\mathrm{AB}, \mathrm{AC}$, and $\mathrm{BC}$. Respondents were randomly assigned to one of these scenarios, and each respondent was given five choice problems, one per product category. For each problem, respondents were shown the alternatives and were asked to rate their attribute performance. To illustrate, in the toothpaste category respondents were first asked to rate the performance of the options in the set on the first attribute (e.g., "How would you rate the cavity-prevention properties of toothpaste A?") and then asked the same question with respect to the other option(s) in the set. Next, respondents were asked to rate the options' performance on the second attribute (i.e., teeth whitening). All ratings were collected using a nine-point scale ( $1=$ low, $5=$ average, $9=$ high $)$.

Following the rating task, respondents were asked to make two choices, conditional on one of the attributes having primary importance. To illustrate, respondents were first asked to choose a toothpaste assuming that cavity prevention is the more important attribute (e.g., "Which of the two products would you choose if your primary concern is cavity protection?") and then to make a choice assuming that teeth whitening was the more important attribute.

In addition to varying the composition of the choice set, this experiment also manipulated the salience of options' pricing. For that purpose, prior to evaluating the options' attribute performance, some of the respondents were asked to indicate how they would expect these options to be priced. Respondents could choose between indicating that a particular option was more expensive than the others or that all options were equally priced ("All options will be equally priced; option A will be the most expensive one; option $\mathrm{B}$ will be the most expensive one; or option $\mathrm{C}$ will be the most expensive one"). The goal of this manipulation was to test the proposition that in the presence of an attribute on which options' performance is not readily observable the strength of compensatory inferences is a function of options' perceived performance on this attribute.

Overall, there were eight scenarios corresponding to the conditions of the experimental design ( 4 choice sets $\times 2$ price-inference conditions). The entire procedure took 10 minutes, on average. At the end of the experiment respondents were debriefed and paid $\$ 5.00$ for participating.

\section{Results Overview}

Each of the 227 respondents evaluated one set of alternatives in each of the five product categories, which yielded 1,135 sets. In each of these sets, respondents rated the performance of each option on both attributes, which yielded six attribute-specific ratings for each trinary set $\mathrm{ABC}$ and four attribute-specific ratings for each of the binary sets $A B$, $\mathrm{AC}$, and $\mathrm{BC}$. Thus, the total number of attribute ratings was 5,156 (four missing data points). Respondents in each of the four scenarios ( $\mathrm{ABC}, \mathrm{AB}, \mathrm{AC}$, and $\mathrm{BC}$ ) were further assigned into two groups. Some were asked to evaluate relative prices of the options prior to rating their performance on nonprice attributes; others were given the attribute-rating task without being asked to compare the options on price. Based on a random assignment, there were 114 respondents in the first condition (569 observations) and 113 in the second (565 observations). Of the 569 responses, 380 indicated that the all-in-one option was likely to be priced higher than the other option(s), while the remaining 189 respondents indicated that either (1) one of the specialized options was likely to be higher priced or (2) that all options were likely to be at price parity. This assignment of respondents into one of the two inferred-price conditions was later used to examine how the presence of attributes on which options' performance is not readily observable influences the strength of compensatory reasoning effects.

A summary of the mean attribute ratings (averaged across product categories) is given in table 1. The attribute performance of choice options is consistent with the representation depicted in figure 1 , such that option $\mathrm{A}$ is differentiated by attribute 1 and option $\mathrm{B}$ is differentiated by attribute 2. The significance of the data patterns shown in table 1 was validated by testing a model in which attribute ratings were given as a function of the choice set, inferredprice dispersion, product category, and all interactions. Because not all observations were truly independent from one another (the same individual rated several product categories and also rated different options within the choice set), the statistical analyses controlled for the within-subject nature of certain aspects of the data (Winer, Brown, and Michels 1991). Because product category did not significantly interact with the dependent variables of interest, for presentation purposes the data are aggregated across categories. Due to the complex nature of the focal effects and the possibility of response biases and/or measurement errors, each of the effects was examined using multiple empirical tests. The data analyses are presented in more detail in the following sections.

\section{Devaluation of the All-in-One Option}

This research argues that the perceived performance of the all-in-one option will decrease in the presence of specialized options $\left(\Delta \mathrm{c}_{1}, \Delta \mathrm{c}_{2}\right)$. There are three strategies to test this proposition. The first test involves comparing the ratings of the all-in-one option $\mathrm{C}$ to the ratings of the specialized options $\mathrm{A}$ and $\mathrm{B}$ in the set $\mathrm{ABC}$. The second strategy is to 
TABLE 1

ATTRIBUTE RATINGS AS A FUNCTION OF THE COMPOSITION OF THE CHOICE SET AND PRICE INFERENCES

\begin{tabular}{|c|c|c|c|c|c|c|}
\hline \multirow[b]{2}{*}{ Salience of unobservable attributes } & \multirow{2}{*}{$\begin{array}{l}\text { Choice } \\
\text { option }\end{array}$} & \multirow[b]{2}{*}{ Attribute } & \multicolumn{4}{|c|}{ Choice sets } \\
\hline & & & $\overline{\mathrm{ABC}}$ & $\mathrm{AC}$ & $\mathrm{BC}$ & $\overline{A B}$ \\
\hline \multicolumn{7}{|l|}{$\begin{array}{l}\text { Scenario 1: Options evaluated only on } \\
\text { featured attributes (no-inference }\end{array}$} \\
\hline & A & 1 & 7.59 & 7.55 & & 7.10 \\
\hline & & 2 & 2.77 & 2.94 & & 3.58 \\
\hline & $\mathrm{B}$ & 1 & 2.93 & & 2.61 & 3.50 \\
\hline & & 2 & 7.43 & & 7.47 & 6.74 \\
\hline & C & 1 & 6.21 & 6.23 & 7.24 & \\
\hline & & 2 & 6.31 & 7.09 & 6.37 & \\
\hline & $N$ & & 145 & 140 & 145 & 135 \\
\hline \multicolumn{7}{|l|}{$\begin{array}{l}\text { Scenario 2A: Options evaluated on an } \\
\text { unobservable attribute (price)-option C } \\
\text { expected to be the most expensive }\end{array}$} \\
\hline $\begin{array}{l}\text { expected to be the most expensive } \\
\text { (high price condition) }\end{array}$ & $A$ & $\begin{array}{l}1 \\
2\end{array}$ & $\begin{array}{l}7.72 \\
2.34\end{array}$ & $\begin{array}{l}7.48 \\
2.48\end{array}$ & & \\
\hline & $\mathrm{B}$ & 1 & 2.60 & & 2.50 & \\
\hline & & 2 & 7.87 & & 7.35 & \\
\hline & C & 1 & 7.18 & 6.81 & 6.92 & \\
\hline & & 2 & 7.31 & 7.06 & 6.98 & \\
\hline & $N$ & & 122 & 124 & 134 & \\
\hline \multirow{8}{*}{$\begin{array}{l}\text { Scenario 2B: Options evaluated on an } \\
\text { unobservable attribute (price)-option C } \\
\text { not expected to be the most expensive } \\
\text { (equal/low price condition) }\end{array}$} & & & & & & \\
\hline & A & 1 & 7.40 & 7.56 & & 6.89 \\
\hline & & 2 & 2.60 & 2.94 & & 3.89 \\
\hline & B & 1 & 2.72 & & 3.10 & 3.69 \\
\hline & & 2 & 7.67 & & 7.29 & 6.78 \\
\hline & C & 1 & 6.40 & 6.25 & 6.23 & \\
\hline & & 2 & 6.51 & 6.83 & 5.87 & \\
\hline & $N$ & & 43 & 36 & 31 & 79 \\
\hline
\end{tabular}

NoTE.-Options' attribute performance is consistent with the representation in fig. 1: option A is differentiated by attribute 1; option B is differentiated by attribute 2 , and option $\mathrm{C}$ is the all-in-one option. Attribute values of choice options are given in the appendix. Numbers in each cell represent mean averages for all observations aggregated across categories and across respondents. The number of observations in each set is given by $N$. Cells in which observations could not be obtained by virtue of the experimental design (e.g., the attractiveness of option $C$ could not be evaluated in context of the set $A B$ ) are left blank.

compare the ratings of the all-in-one option across the binary and trinary choice sets-a strategy that compares the ratings of option $\mathrm{C}$ in the set $\mathrm{ABC}$ to the ratings of option $\mathrm{C}$ in sets $\mathrm{AC}$ and $\mathrm{BC}$. Finally, the third strategy involves comparing the attribute ratings of the all-in-one option across the two binary sets AC and BC. The data analyses corresponding to these three strategies are presented in more detail below.

The first test of the prediction that the perceived performance of the all-in-one option will decrease in the presence of specialized options compared the individual-specific attribute ratings of option $\mathrm{C}$ to the attribute ratings of options $\mathrm{A}$ and $\mathrm{B}$ in the set $\mathrm{ABC}$. In particular, this prediction implies that $\mathrm{C} 1_{\mathrm{ABC}}<\mathrm{A} 1_{\mathrm{ABC}}$ and $\mathrm{C} 2_{\mathrm{ABC}}<\mathrm{B} 2_{\mathrm{ABC}}$, where $\mathrm{C} 1_{\mathrm{ABC}}$ is the rating of option $\mathrm{C}$ on attribute 1 in the set $\mathrm{ABC}$ and $\mathrm{C} 2_{\mathrm{ABC}}$ is the rating of option $C$ on attribute 2 in the same set. The data show that the mean ratings were $M_{\mathrm{Cl}(\mathrm{ABC})}=6.21$ versus $M_{\mathrm{A} 1(\mathrm{ABC})}=7.59(t=-9.6 ; p<.001)$ when comparing $\mathrm{C} 1_{\mathrm{ABC}}$ and $\mathrm{A} 1_{\mathrm{ABC}}$ and $M_{\mathrm{C} 2(\mathrm{ABC})}=6.31$ versus $M_{\mathrm{B} 2(\mathrm{ABC})}=$ $7.43(t=-6.7 ; p<.001)$ when comparing $\mathrm{C} 22_{\mathrm{ABC}}$ and $\mathrm{B} 2_{\mathrm{ABC}}$. The difference in the attribute ratings of option $\mathrm{C}$ was nonsignificant, indicating that the devaluation effect was symmetric across attributes $\left(M_{\mathrm{Cl}(\mathrm{ABC})}=6.21\right.$ versus $\left.M_{\mathrm{C} 2(\mathrm{ABC})}=6.31 ; p>.20\right)$. These data are consistent with the experimental predictions.

A further test of the impact of specialized options on the all-in-one option compared the ratings of the all-inone option $\mathrm{C}$ in the trinary set $\mathrm{ABC}$ and its ratings in the binary sets $\mathrm{AC}$ and $\mathrm{BC}$. Of particular interest are the attribute-rating comparisons across scenarios with and without a specialized option: $\mathrm{C} 1_{\mathrm{ABC}}$ versus $\mathrm{C} 1_{\mathrm{BC}}$ and $\mathrm{C} 2_{\mathrm{ABC}}$ versus $\mathrm{C} 22_{\mathrm{AC}}$. It was proposed that adding option $\mathrm{A}$ to the set $\mathrm{BC}$ should lead to a devaluation of option $\mathrm{C}$ on attribute 1 because option $A$ is specialized on this attribute, as well as a devaluation of option $\mathrm{C}$ on attribute 2 , on which option $\mathrm{B}$ is specialized. The data show that option $\mathrm{C}$ had lower attribute ratings in the trinary set than in either of the binary sets. The mean rating of option $\mathrm{C}$ on attribute 1 in the set $\mathrm{ABC}$ was $M_{\mathrm{Cl}(\mathrm{ABC})}=6.21$, significantly lower than its rating of $M_{\mathrm{C} 1(\mathrm{BC})}=7.24$ in the set $\mathrm{BC}(F(1,166)=$ $21.97 ; p<.001)$. Similarly, the mean rating of option $\mathrm{C}$ on the second attribute in the set $\mathrm{ABC}$ was $M_{\mathrm{C} 2(\mathrm{ABC})}=$ 6.31, significantly lower than its rating of $M_{\mathrm{C} 2(\mathrm{AC})}=$ 7.09 in the set $\mathrm{AC}(F(1,165)=13.27 ; p<.001)$. 
The third test of the prediction that the perceived performance of the all-in-one option will decrease in the presence of specialized options compared the attribute ratings of option $\mathrm{C}$ across the two binary sets $\mathrm{AC}$ and $\mathrm{BC}$. Consistent with the experimental predictions, the presence of a specialized alternative in each of the sets $\mathrm{AC}$ and $\mathrm{BC}$ should lead to asymmetric devaluation of option $\mathrm{C}$ on the attribute featured by the specialized option. Thus, option C's ratings on attribute 1 should be lower in the set AC than in the set $\mathrm{BC}$, and vice versa for attribute 2 . The data show that the mean rating of option $\mathrm{C}$ on attribute 1 was significantly lower in the set $\mathrm{AC}$ than in the set $\mathrm{BC}\left(M_{\mathrm{C} 1(\mathrm{AC})}=6.23\right.$ versus $\left.M_{\mathrm{C} 1(\mathrm{BC})}=7.24 ; F(1,159)=21.09 ; p<.001\right)$. Similarly, the mean rating of option $\mathrm{C}$ on the second attribute was significantly lower in the set $\mathrm{BC}$ than in the set $\mathrm{AC}$ $\left(M_{\mathrm{C} 2(\mathrm{BC})}=6.37\right.$ vs. $M_{\mathrm{C} 2(\mathrm{AC})}=7.09 ; \quad F(1,159)=10.63$; $p<.005)$.

Considered together, the three tests offer converging empirical evidence in support of the proposition that specialized alternatives lead to a compensatory devaluation of the allin-one option.

\section{Polarization of the Specialized Options}

This research argued that the attribute ratings of a specialized option are polarized by the presence of an all-inone option in a way that enhances the perceived performance of the specialized option on its differentiating attribute $\left(\Delta \mathrm{a}_{1}\right.$, $\left.\Delta \mathrm{b}_{2}\right)$ and detracts from its perceived performance on the secondary attribute $\left(\Delta \mathrm{a}_{2}, \Delta \mathrm{b}_{1}\right)$. This proposition was tested by comparing the attribute ratings of the specialized options $\mathrm{A}$ and $\mathrm{B}$ as a function of the presence of an all-in-one option.

The test of the compensatory enhancement effect compared the ratings of options $\mathrm{A}$ and $\mathrm{B}$ on their differentiating attributes across sets $\mathrm{ABC}$ and $\mathrm{AB}$. The data show that the mean rating of option $\mathrm{A}$ in the set $\mathrm{ABC}$ was $M_{\mathrm{A} 1(\mathrm{ABC})}=$ 7.59, which was significantly greater than this option's ratings in the absence of the all-in-one option $M_{\mathrm{A} 1(\mathrm{AB})}=$ $7.10 ; \quad(F(1,127)=4.11 ; p<.05)$. Similarly, option B was rated significantly higher on its differentiating attribute in the presence of the all-in-one option $\mathrm{C}$ than when option $\mathrm{C}$ was absent $\left(M_{\mathrm{B} 2(\mathrm{ABC})}=7.43\right.$ vs. $M_{\mathrm{B} 2(\mathrm{AB})}=6.74$; $F(1,127)=8.23 ; p<.01)$. A further test of the compensatory enhancement effect compared the attractiveness of options $\mathrm{A}$ and $\mathrm{B}$ across sets $\mathrm{AB}$ and $\mathrm{AC} / \mathrm{BC}$. In this context, the specialized options $A$ and $B$ are predicted to be perceived as more attractive on their differentiating attributes in the presence of an all-in-one alternative. The data were consistent with this prediction: option A was perceived to be more attractive on its differentiating attribute in the set $\mathrm{AC}$ than in the set $\mathrm{AB}\left(M_{\mathrm{Al}(\mathrm{AC})}=7.55\right.$ vs. $M_{\mathrm{A} 1(\mathrm{AB})}=7.10$; $F(1,120)=3.91 ; p=.05)$. Similarly, option B was rated higher on its differentiating attribute in the set $\mathrm{BC}$ than in the set $\mathrm{AB}\left(M_{\mathrm{B} 2(\mathrm{BC})}=7.47\right.$ vs. $M_{\mathrm{B} 2(\mathrm{AB})}=6.74 ; F(1,121)=$ $7.99 ; p<.01)$.

The test of the compensatory devaluation effect compared the ratings of options $\mathrm{A}$ and $\mathrm{B}$ on their nondifferentiating attributes across sets $\mathrm{ABC}$ and $\mathrm{AB}$. The data show that option A was perceived as less attractive on its nondifferentiating attribute in the set $\mathrm{ABC}$ than in the set $\mathrm{AB}$ $\left(M_{\mathrm{A} 2(\mathrm{ABC})}=2.77\right.$ vs. $M_{\mathrm{A} 2(\mathrm{AB})}=3.58 ; \quad F(1,127)=9.55$; $p<.005)$. Similarly, option B was perceived as less attractive on its nondifferentiating attribute in the absence of the all-in-one option than when the all-in-one option was present $\left(M_{\mathrm{B} 1(\mathrm{ABC})}=2.93\right.$ vs. $M_{\mathrm{B} 1(\mathrm{AB})}=3.50 ; F(1,127)=4.68$; $p<.005)$. A further test of the compensatory devaluation effect compared the attractiveness of options A and B across sets $\mathrm{AB}$ and $\mathrm{AC} / \mathrm{BC}$. The data show that the nondifferentiating attribute of option $\mathrm{A}$ received lower ratings in the set $\mathrm{AC}$ than in the set $\mathrm{AB}\left(M_{\mathrm{A} 2(\mathrm{AC})}=2.94\right.$ vs. $M_{\mathrm{A} 2(\mathrm{AB})}=$ $3.58 ; F(1,120)=4.86 ; p<.05)$. Similarly, the nondifferentiating attribute of option $\mathrm{B}$ was rated less attractive in the set $\mathrm{BC}$ than in the set $\mathrm{AB}\left(M_{\mathrm{B} 1(\mathrm{BC})}=2.61\right.$ vs. $M_{\mathrm{B} 1(\mathrm{AB})}=$ $3.50 ; F(1,121)=9.95 ; p<.005)$.

Overall, the experimental data support the proposition that adding an all-in-one option to a choice set comprising specialized options is likely to lead to a compensatory enhancement of the performance of the specialized options on differentiating attributes and a compensatory devaluation of the performance of the specialized options on nondifferentiating attributes.

\section{Inferring Options' Performance on Unobservable Attributes}

This research argued that the strength of compensatory inferences is a function of the perceived performance of the options on unobservable attributes. In particular, the devaluation of the all-in-one option in the presence of specialized alternatives was predicted to be less pronounced when the all-in-one option is perceived to be inferior on the unobservable attribute. This prediction was tested by making one of the unobservable attributes (price) salient and examining the impact of consumers' price perceptions on the strength of the compensatory inferences. In this context, it was expected that respondents who expected the all-in-one option to be higher priced would be less likely to devalue this option than respondents who expected the all-in-one option to be priced at parity or lower than the specialized options.

Recall that respondents were randomly assigned to either the no-inference condition or the price-inference condition. Based on their responses, individuals in the price-inference condition were further assigned to two groups: a "high price" group made up of respondents who inferred that the all-inone option was likely to be the most expensive option in the set and a "low price" group made up of respondents who expected the all-in-one option to be priced at parity or less than the other options. In this context, the impact of price inferences on the strength of the compensatory reasoning effects was tested by comparing the dispersion of attribute ratings across the control and "high price" conditions, whereby the compensatory devaluation of the all-inone option should be greater in the control than in the high price condition. The strategy for testing this prediction was similar to the strategy used in testing the devaluation of the 
all-in-one option: the impact of price inferences on the dispersion of attribute ratings of options was evaluated (1) within the set $\mathrm{ABC}$, (2) across sets $\mathrm{ABC}$ and $\mathrm{AC} / \mathrm{BC}$, and (3) across sets AC and BC.

A comparison of attribute ratings of the all-in-one option $\mathrm{C}$ between the high price and no-inference conditions shows that in the set $\mathrm{ABC}$ option $\mathrm{C}$ was rated higher on both attributes when it was perceived to be higher priced $\left(M_{\mathrm{C} 1(\mathrm{ABC})}=7.18\right.$ and $\left.M_{\mathrm{C} 2(\mathrm{ABC})}=7.31\right)$ than when no price inferences were drawn $\left(M_{\mathrm{C} 1(\mathrm{ABC})}=6.21\right.$ and $M_{\mathrm{C} 2(\mathrm{ABC})}=$ 6.31). The difference in attribute evaluations of option $C$ was significant for both attributes $(F(1,86)=19.37 ; p<$ .001 for attribute 1 and $F(1,86)=16.93 ; p<.001$ for attribute 2). Similarly, in sets AC and BC, option C had higher attribute ratings when inferred to be higher priced $\left(M_{\mathrm{C} 1(\mathrm{AC})}=6.81\right.$ and $\left.M_{\mathrm{C} 2(\mathrm{BC})}=6.98\right)$ than when there was no price inference $\left(M_{\mathrm{Cl}(\mathrm{AC})}=6.23\right.$ and $M_{\mathrm{C} 2(\mathrm{BC})}=6.37$; $F(1,79)=6.18 ; p<.05$ and $F(1,80)=5.55 ; p<.05)$. Furthermore, inferred-price ranking influenced not only the ratings of the all-in-one option $\mathrm{C}$ but also its relative attractiveness vis-à-vis the specialized options $\mathrm{A}$ and $\mathrm{B}$. Thus, the difference in attractiveness of options $\mathrm{A}$ and $\mathrm{C}$ was $\Delta M_{\mathrm{A} 1-\mathrm{Cl}(\mathrm{ABC})}=.54$ in the high price condition, compared with $\Delta M_{\mathrm{A} 1-\mathrm{Cl}(\mathrm{ABC})}=1.38$ in the no-inference condition $(F(1,86)=12.56 ; p<.005)$. Similarly, the difference in attractiveness of options $\mathrm{B}$ and $\mathrm{C}$ was $\Delta M_{\mathrm{B} 2-\mathrm{C} 2(\mathrm{ABC})}=.56$ in the high price condition, compared with $\Delta M_{\mathrm{B} 2-\mathrm{C} 2(\mathrm{ABC})}=$ 1.12 in the no-inference condition $(F(1,86)=4.32 ; p<$ $.05)$. These data show that the devaluation of the all-in-one option was mitigated by the inferred price-inferiority (i.e., higher price) of this option-a finding consistent with the experimental predictions.

The impact of price inferences on the strength of the compensatory reasoning effects was further tested by comparing the attribute ratings of the all-in-one option $\mathrm{C}$ in the set $\mathrm{ABC}$ to its ratings in sets $\mathrm{AC}$ and $\mathrm{BC}$ across the high price and the no-inference conditions. The data show that the difference in attractiveness of option $\mathrm{C}$ across sets $\mathrm{ABC}$ and $\mathrm{AC}$ was $\Delta M_{\mathrm{C} 2(\mathrm{ABC})-\mathrm{C} 2(\mathrm{AC})}=.26$ in the high price condition, compared with $\Delta M_{\mathrm{C} 2(\mathrm{ABC})-\mathrm{C} 2(\mathrm{AC})}=-.78$ in the noinference condition $(F(1,165)=9.85 ; p<.005)$ - a finding consistent with the experimental predictions. Similarly, the difference in attractiveness of option $C$ across sets $\mathrm{ABC}$ and $\mathrm{AB}$ was $\Delta M_{\mathrm{Cl}(\mathrm{ABC})-\mathrm{Cl}(\mathrm{BC})}=.26$ in the high price condition, compared with $\Delta M_{\mathrm{Cl}(\mathrm{ABC})-\mathrm{Cl}(\mathrm{BC})}=-1.02$ in the no-inference condition $(F(1,86)=18.04 ; p<.001)$.

The impact of price inferences on the strength of the compensatory reasoning effect was also tested by comparing the attribute ratings of option $\mathrm{C}$ in sets $\mathrm{AC}$ and $\mathrm{BC}$ across the high price and the no-inference conditions. The data show that the difference in attractiveness of option $\mathrm{C}$ across sets $\mathrm{AC}$ and $\mathrm{BC}$ was $\Delta M_{\mathrm{Cl}(\mathrm{AC})-\mathrm{Cl}(\mathrm{BC})}=-.12$ in the high price condition, compared with $\Delta M_{\mathrm{C} 1(\mathrm{AC})-\mathrm{C} 1(\mathrm{BC})}=-1.01$ in the no-inference condition $(F(1,159)=8.32 ; p<.005)$. Similarly, the difference in attractiveness of option $\mathrm{C}$ across sets $\mathrm{ABC}$ and $\mathrm{BC}$ was $\Delta M_{\mathrm{C} 2(\mathrm{BC})-\mathrm{C} 2(\mathrm{AC})}=-.08$ in the high price condition, compared with $\Delta M_{\mathrm{C} 2(\mathrm{BC})-\mathrm{C} 2(\mathrm{AC})}=-.71$ in the no-inference condition $(F(1,165)=3.32 ; p<.10)$.

The potential artifacts of the price-inference manipulation were also tested by examining the strength of the compensatory reasoning effects across the two price-inference conditions. In this context, this research argued that the compensatory devaluation effect will be weaker for respondents who rated option $\mathrm{C}$ as being the highest priced than for respondents who did not infer option $\mathrm{C}$ to be the most expensive. The data show that option $\mathrm{C}$ was rated higher in the high price condition $\left(M_{\mathrm{Cl}(\mathrm{ABC})}=7.18\right.$ and $M_{\mathrm{C} 2(\mathrm{ABC})}=$ $7.31 ; F(1,86)=5.65 ; p<.05)$ than in the equal/low price condition $\left(M_{\mathrm{C} 1(\mathrm{ABC})}=6.40\right.$ and $M_{\mathrm{C} 2(\mathrm{ABC})}=6.51 ; F(1,86)=$ $6.99 ; p<.05)$. Further analysis shows that the difference in the attractiveness of option $\mathrm{C}$ and options $\mathrm{A}$ and $\mathrm{B}$ was also less pronounced for respondents in the high price condition than for those in the equal/low price condition. Thus, in the high price condition the difference in attribute evaluations across options $\mathrm{A}$ and $\mathrm{C}$ was $\Delta M_{\mathrm{A} 1-\mathrm{C} 1(\mathrm{ABC})}=$ .54 and $\Delta M_{\mathrm{B} 2-\mathrm{C} 2(\mathrm{ABC})}=.56$ across options $\mathrm{B}$ and $\mathrm{C}$. In contrast, in the equal/low price condition the difference in attribute evaluations was greater: $\Delta M_{\mathrm{A} 1-\mathrm{Cl}(\mathrm{ABC})}=1.00$ and $\Delta M_{\mathrm{B} 2-\mathrm{C} 2(\mathrm{ABC})}=1.16$. The combined effect of the differences in the devaluation effect was significant $(F(2,86)=3.84$; $p<.05)$, lending further support to the proposition that the devaluation of the all-in-one option is mitigated by the inferred inferiority of this option on price.

Considered together, the above findings support the proposition that the compensatory devaluation of the all-in-one option will be less pronounced when this option is perceived to be inferior on an attribute with not readily observable values. This prediction was further tested by analyzing respondents' choices across experimental conditions. Recall that respondents were asked to make two contingent choice decisions (one assuming attribute 1 to be most important, and one assuming attribute 2 to be most important). The pattern of dispersion of choice shares across the experimental conditions was consistent with the attribute ratings shown in figure 1, and the relevant differences across the experimental conditions were significant, replicating the ratings data. These findings support the experimental predictions and further document compensatory effects across different preference-elicitation procedures (ratings and choice).

\section{Discussion}

The data furnished by experiment 1 support the proposition that consumers evaluate the specialized and all-in-one options in a compensatory fashion. In particular, the attractiveness of the attributes differentiating the all-in-one option was found to decrease in the presence of specialized options. The data further show that compensatory reasoning also leads to polarization of the attributes describing specialized options: it enhances the attractiveness of the differentiating attribute of a specialized option and devalues this option on its secondary attributes. Moreover, the strength of compensatory inferences was shown to be a function of consumer inferences about the option's performance on unobservable 
attributes. Thus, merely asking respondents to infer options' performance on an unobservable attribute resulted in a significant decrease in compensatory devaluation effects. In this context, the compensatory effects were pronounced when the inferred performance was inconsistent with the readily available attribute information than when the inferred performance was consistent with the available information.

A further test of the compensatory reasoning hypothesis can be offered by examining the dispersion of attribute ratings across choice alternatives as a function of price. Prior research on price-quality inferences has shown that increasing the price of an option is also likely to increase its perceived performance on nonprice attributes (Huber and McCann 1982; Johnson 1987; Johnson and Levin 1985; Lichtenstein and Burton 1989). Building on these findings, consumers' reliance on the zero-sum heuristic can be further tested by examining the impact of a price increase on the relative attractiveness of the all-in-one and the specialized options.

The logic of the argument that varying price is likely to have a differential impact on the perceived performance of the specialized and all-in-one options is derived from the concavity of the value function, which implies that an increase in an object's value on a particular attribute is associated with a decrease in this attribute's marginal utility (Bernoulli 1738; Kahneman and Tversky 1979; Tversky and Kahneman 1991). The principle of diminishing sensitivity, implied by the concavity of the value function, is consistent with the psychophysical principle that sensitivity to changes along a particular attribute is reduced as the magnitude of that attribute increases (Torgerson 1958). In marketing, the diminishing sensitivity argument has been demonstrated in the context of new product development, whereby new product features have been shown to contribute more value to relatively inferior products than to relatively superior products (Nowlis and Simonson 1996; see also Chernev and Hamilton 2007).

The differential impact of varying price on the perceived performance of the specialized and all-in-one options is illustrated in figure 2 . In the absence of compensatory inferences, both options $\mathrm{A}$ and $\mathrm{C}$ are perceived to have equal ratings on attribute 1 , as shown in figure $1 A$. Therefore, in the absence of compensatory enhancement and devaluation effects, the impact of raising price on options' perceived performance should be the same for the all-in-one and the specialized options, as shown in figure $2 A$. In contrast, compensatory reasoning and the associated devaluation and enhancement effects are likely to make the specialized option A more attractive than the all-in-one option $\mathrm{C}$ on attribute 1 (see fig. $1 B$ ). If this indeed is the case, then pricing each of these options at a premium should have a differential impact on their perceived performance. In particular, the diminishing sensitivity argument predicts that the increase in the relative attractiveness of the devalued option $\mathrm{C}$ will be greater than the increase in the enhanced option $\mathrm{A}$ (see fig. 2B).
The essence of the above argument is that if the zerosum heuristic leads to a polarization of an option's performance on differentiating attributes then increasing the price of each of these options by the same amount should have an asymmetric impact on the options' performance on nonprice attributes; this, in turn, will lead to a greater improvement in attribute performance of the all-in-one alternative relative to specialized options. Because the difference in options' attribute performance is a prerequisite for the predicted asymmetric impact of price, the presence of a significant asymmetric impact of price can be viewed as evidence supporting the zero-sum heuristic. The validity of this prediction is tested in the following experiment.

\section{EXPERIMENT 2}

The goal of this experiment was to further test the compensatory reasoning hypotheses and, in particular, to test the proposition that the perceived attractiveness and choice share of the all-in-one option can be increased by pricing this option at a premium in relation to the specialized options. This prediction was tested by employing four experimental conditions: a base condition in which all options were priced at parity and three conditions in which one of the options was priced higher than the others. The experimental method and empirical results are presented in more detail in the following sections.

\section{Method}

Respondents, 74 Northwestern University students, were recruited to participate in a study on consumer decision making and were informed that the choice task involved making hypothetical purchase decisions. Four product categories were used as stimuli: laundry detergent, shaving cream, toothpaste, and vitamin supplements. Choice alternatives were described on either one (for specialized options) or two (in case of the all-in-one option) attributes and priced as shown in the appendix, table A2.

Respondents were randomly assigned to one of the four experimental conditions that differed in terms of the distribution of options' prices. All sets were made up of three options: two specialized options (A and B) and an all-inone option $(\mathrm{C})$. Options in one of the conditions (control condition) were all priced at parity, while in the other three conditions one of the options was priced higher than the others $\left(\mathrm{ABC}, \mathrm{A}_{+} \mathrm{BC}, \mathrm{AB}_{+} \mathrm{C}, \mathrm{ABC}_{+}\right.$, with the higher priced option marked with $\mathrm{a}+$ ). Each respondent made four choices, one in each product category.

For each product category, respondents were asked to choose one of the three options and then rate all the options' performance on each of the two attributes on a nine-point scale (same as in the first experiment). At the end of the experiment, respondents were debriefed and paid for participating. 
FIGURE 2

COMPENSATORY ENHANCEMENT AND DEVALUATION EFFECTS IN CHOICE: COMPENSATORY REASONING AS A FUNCTION OF PRICE INFORMATION

A. The Impact of Price on Product Evaluations in the Absence of Compensatory Inferences

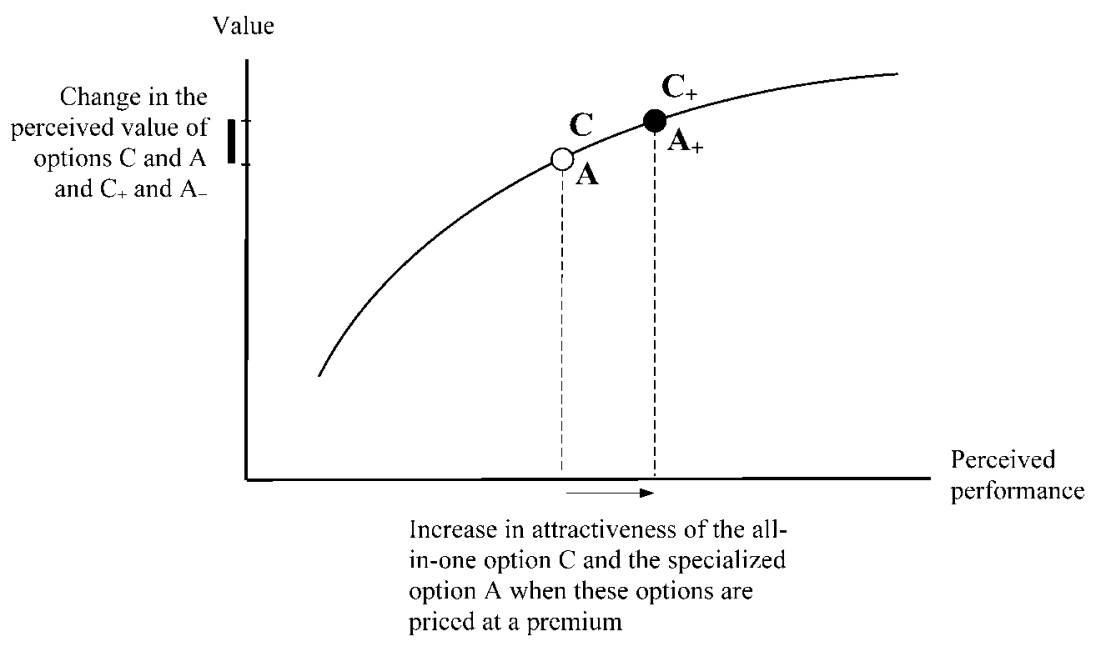

B. The Impact of Price on Product Evaluations in the Presence of Compensatory Inferences

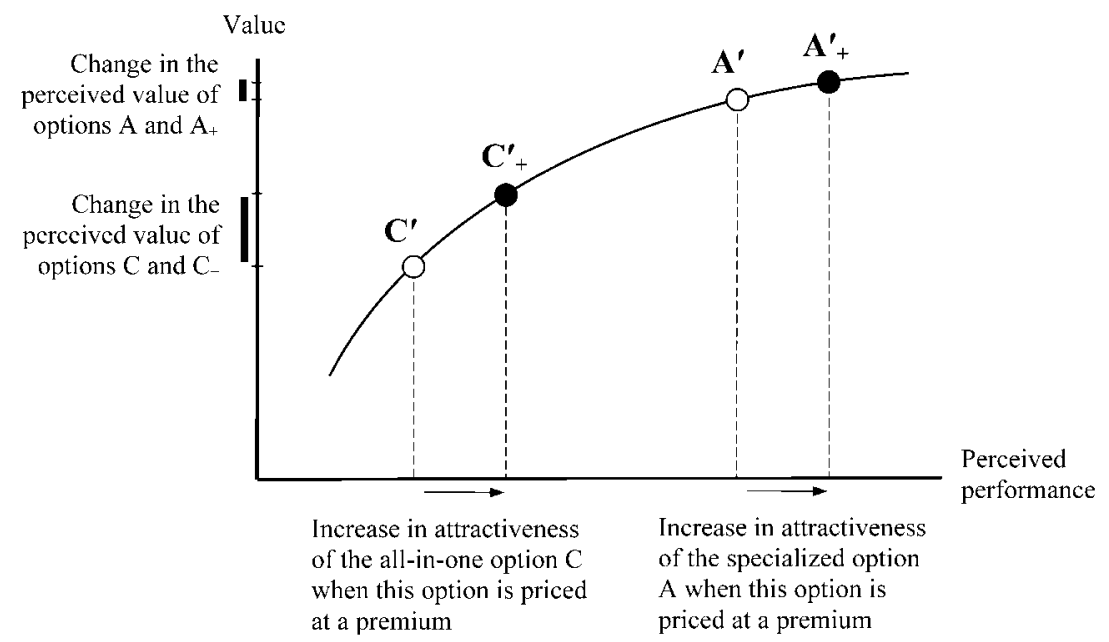

NOTE.-The graph reflects options' performance on one of the two attributes differentiating choice alternatives (attribute 1 in fig. 1). Option A is the specialized option and option $C$ is the all-in-one option. Options $A_{+}$and $C_{+}$denote the higher priced versions of options $A$ and $C$.

\section{Results}

The Impact of Price Dispersion on Attribute Inferences. Each of the 74 respondents evaluated one set of alternatives in each of the four product categories, which yielded 296 sets. For each set, respondents rated the performance of each option on both attributes, yielding a total of 1,776 observations (six attribute-specific ratings for each set).
A summary of the mean attribute ratings (averaged across product categories) is given in table 2. The significance of the data patterns shown in the table was validated by testing a model in which attribute ratings were given as a function of price dispersion, option type (specialized vs. all-in-one), product category, and their interactions. The data analyses are presented in more detail in the following sections.

Consistent with the compensatory reasoning argument, the data show that when options were priced at parity, re- 
TABLE 2

ATTRIBUTE RATINGS AS A FUNCTION OF PRICE DISPERSION (EXPERIMENT 2)

\begin{tabular}{lllll}
\hline \hline & \multicolumn{5}{c}{ Price } \\
\cline { 2 - 5 } Option/attribute & Equal & $\mathrm{C}_{+}$ & $\mathrm{A}_{+}$ & $\mathrm{B}_{+}$ \\
\hline $\mathrm{A}_{1}$ & 7.53 & 7.38 & 7.97 & 7.04 \\
$\mathrm{~A}_{2}$ & 2.73 & 3.14 & 3.12 & 3.11 \\
$\mathrm{~B}_{1}$ & 2.91 & 2.95 & 2.96 & 3.42 \\
$\mathrm{~B}_{2}$ & 7.42 & 7.62 & 7.09 & 7.91 \\
$\mathrm{C}_{1}$ & 5.99 & 6.89 & 5.72 & 6.5 \\
$\mathrm{C}_{2}$ & 6.14 & 7.01 & 6.39 & 5.72 \\
\hline
\end{tabular}

NotE.-Option $A$ is differentiated by attribute $1\left(A_{1}\right)$, option $B$ is differentiated by attribute $2\left(B_{2}\right)$, and option $C$ is the all-in-one option differentiated by both attributes $\left(C_{1}\right.$ and $\left.C_{2}\right)$. Numbers in each cell represent mean averages for all observations aggregated across categories and across respondents. In each set, $N=74$.

spondents were likely to devalue the all-in-one option relative to the specialized options. In particular, the compensatory reasoning argument implies that $C_{1}<A_{1}$ and $C_{2}<$ $B_{2}$, where $\mathrm{C}_{1}$ is the rating of option $\mathrm{C}$ on attribute 1 and $\mathrm{C}_{2}$ is the rating of option $\mathrm{C}$ on attribute 2 . Consistent with this prediction, the data show that $M_{\mathrm{C} 1}=5.99$ versus $M_{\mathrm{A} 1}=$ $7.53(t=-10.07 ; p<.001)$ when comparing $\mathrm{C}_{1}$ and $\mathrm{A}_{1}$, and $M_{\mathrm{C} 2}=6.14$ versus $M_{\mathrm{B} 2}=7.42(t=-7.78 ; p<.001)$ when comparing $\mathrm{C}_{2}$ and $\mathrm{B}_{2}$.

The data further show that higher price was also associated with an increase in the perceived performance of the all-in-one option on both attributes $\left(M_{\mathrm{Cl}(\mathrm{ABC})}=\right.$ 5.99 vs. $M_{\mathrm{Cl}(\mathrm{ABC}+)}=6.89 ; F(1,219)=28.34 ; p<.001$, and $M_{\mathrm{C} 2(\mathrm{ABC})}=6.124$ vs. $M_{\mathrm{C} 2(\mathrm{ABC}+)}=7.01 ; F(1,219)=$ $19.03 ; p<.001)$. A similar increase in perceived performance occurred when the higher priced option was one of the specialized alternatives. Thus, respondents were more likely to rate the specialized option $\mathrm{A}$ as superior on the differentiating attribute $\mathrm{A}_{1}$ when it was priced at a premium than in a scenario where all options were priced at parity $\left(M_{\mathrm{Al}(\mathrm{ABC})}=7.53\right.$ vs. $M_{\mathrm{Al}(\mathrm{ABC}+)}=7.97 ; F(1,219)=6.94$; $p<.01)$. In the same vein, option $\mathrm{B}$ was rated superior on the differentiating attribute $\mathrm{B}_{2}$ when priced at premium than when priced at parity $\left(M_{\mathrm{B} 2(\mathrm{ABC})}=7.42\right.$ vs. $M_{B 2(\mathrm{ABC}+)}=$ 7.91; $F(1,219)=5.80 ; p<.05)$.

More important, the compensatory reasoning argument predicts that the enhancement from premium pricing is likely to be more pronounced for the all-in-one option than for either of the specialized options. This prediction is tested by comparing the magnitude of the increase in attractiveness of the all-in-one and the specialized options. For that purpose, for each respondent the increase in the perceived attractiveness of the premium-priced option on the differentiating attribute was compared across the specialized and the all-in-one option. In particular, the average increase in the attractiveness of the specialized option differentiated by attribute 1 was less pronounced than the increase in the attractiveness of the all-in-one option on the same attribute when this option was higher priced $\left(M_{\mathrm{A} 1(\mathrm{~A}+\mathrm{BC})}=.44 \mathrm{vs}\right.$. $\left.M_{\mathrm{Cl}(\mathrm{ABC}+)}=.90\right)$. The corresponding effect for the second attribute displayed a similar pattern $\left(M_{\mathrm{B} 2(\mathrm{AB}+\mathrm{C})}=.49 \mathrm{vs}\right.$. $\left.M_{\mathrm{C} 2(\mathrm{ABC}+)}=.88\right)$, and the asymmetric nature of the enhancement effect was significant across the two attributes $(F(1,219)=7.06 ; p<.01)$. This finding provides further support for the proposed compensatory reasoning mechanism of the observed effects.

The Impact of Price Dispersion on Choice. Each of the 74 respondents selected one of the alternatives in each of the four sets, which yielded 296 observations. The choice shares of options A, B, and C in each of the four conditions are summarized in table 3 . The data show that the choice share of the all-in-one option was greater when one of the options was priced at a premium than when all options were priced at parity. In particular, the choice share of the all-inone option $\mathrm{C}$ was greater when its price exceeded that of the specialized options than when it was priced at parity with the other options $\left(54.1 \%\right.$ vs. $74.3 \% ; \chi^{2}(1)=6.47$; $p=.01)$. This finding is consistent with the notion that the attractiveness of the all-in-one option on the differentiating attributes is likely to increase when this option is priced at a premium. More important, the increase in the choice share of the all-in-one option (relative to the price-parity condition) was significantly greater when this option was the highest priced option than when either of the specialized options was highest priced $(54.1 \%$ vs. $74.3 \%$ vs. $60.8 \%$ vs. $\left.58.1 \% ; \chi^{2}(1)=6.05 ; p=.01\right)$.

Furthermore, the impact of parity pricing on choice shares of the alternatives was asymmetric for the all-in-one and the specialized options. In particular, while increasing the price of the all-in-one option resulted in an increase in its choice share, the impact of increasing the price of the specialized options was less consistent, leading to a minor decrease in the share of the higher priced option A (25.7\% vs. $24.3 \%)$ and an increase in the share of the higher priced option $\mathrm{B}$ (20.3\% vs. $25.7 \%)$. In this context, the increase in the choice share of the all-in-one option was significantly greater than the increase in the share of the specialized options $\left(\chi^{2}(1)=15.64 ; p<.001\right)$, lending further support for the experimental predictions.

\section{Discussion}

The data furnished by this experiment show that the perceived attribute performance of the all-in-one option is likely

TABLE 3

CHOICE SHARE AS A FUNCTION OF PRICE DISPERSION (EXPERIMENT 2)

\begin{tabular}{lllll}
\hline \hline & \multicolumn{5}{c}{ Price } \\
\cline { 2 - 5 } Option & Equal & $\mathrm{C}_{+}$ & $\mathrm{A}_{+}$ & $\mathrm{B}_{+}$ \\
\hline $\mathrm{A}$ & 25.7 & 14.9 & 24.3 & 16.2 \\
$\mathrm{~B}$ & 20.3 & 10.8 & 14.9 & 25.7 \\
$\mathrm{C}$ & 54.1 & 74.3 & 60.8 & 58.1 \\
\hline \multicolumn{4}{r}{ NoTE.-Percentages in each of the cells indicate the choice share of the } \\
corresponding option. For all cells, $N=74$.
\end{tabular}


to be greater when this option is priced at a premium relative to specialized options than when it is priced at parity. More important, the increase in the perceived attribute performance associated with premium pricing was greater for the all-in-one option than for specialized options. This asymmetric nature of the impact of price on performance ratings and choice suggests that the observed effects cannot be accounted for solely by price-quality inferences. Indeed, in the absence of devaluation of the all-in-one option, it is difficult to account for the asymmetric increase in the attractiveness of the all-in-one versus the specialized options. Overall, this data pattern is consistent with the proposition that increasing the price of the all-in-one option introduces a dimension on which this option is deficient, which, in turn, eliminates the basis for compensatory reasoning and decreases the likelihood of consumers devaluing that option.

An important consideration raised by the pricing manipulation is that the dispersion of options' prices might have changed the nature of the trade-offs made by respondents. Indeed, when all options are priced at parity and option $\mathrm{C}$ is perceived to be inferior on the attributes dominated by specialized options, consumers are faced with a trade-off between maximizing the performance on a particular attribute (choosing one of the specialized options) and settling for moderate quantities of each attribute (choosing the allin-one option). In contrast, when the all-in-one option is priced at a premium (and hence is less likely to be devalued), it will be perceived as combining the "good" features of the specialized options, which then eliminates the need for trading off the two performance-related attributes. Instead, the decision now involves a trade-off between performance and price. The expected increase in the share of the all-in-one option in this case is consistent with the research documenting consumer preference for performance (quality) over price (Carmon and Simonson 1998; Hardie, Johnson, and Fader 1993; Simonson, Nowlis, and Lemon 1993; Simonson and Tversky 1992). In this context, choosing the all-in-one alternative eliminates the need to trade off two performancerelated attributes and instead positions the all-in-one option as the price-based compromise. It is important to note, however, that because the actual attribute values of the specialized and the all-in-one options are identical, the proposition that varying price might have changed the nature of the trade-offs is meaningful only in the presence of compensatory inferences.

\section{GENERAL DISCUSSION}

This research examines consumer reactions to two common positioning strategies: a specialized strategy in which an option is differentiated by a single feature, and an allin-one strategy in which an option is differentiated by a combination of features. It was proposed that when making choices from sets comprising both specialized and all-inone options, consumers are likely to adopt a zero-sum heuristic, in which they equate the overall attractiveness of choice alternatives and evaluate ambiguous information in a compensatory fashion.
Two empirical studies reported in this article demonstrate that the perceived attractiveness of the attributes differentiating the all-in-one option tends to decrease in the presence of specialized options. In contrast, adding an all-in-one option to a set made up of specialized options tends to polarize the perceived performance of these options: it enhances the attractiveness of the attributes differentiating each of the specialized options, while devaluing the performance of these options on their secondary, nonfeatured attributes. These compensatory enhancement and devaluation effects were shown to be a function of options' perceived performance on unobservable attributes, such that these effects were less pronounced when the options' performance on unobservable attributes was inferred to be inconsistent with their performance on the readily observed attributes.

To account for the reported effects, this research introduced the zero-sum heuristic as a general mechanism for drawing compensatory evaluations in choice. Here, the zerosum heuristic is defined as a context-based inference strategy in which an option's values are derived from the other alternatives in the set. Thus, the zero-sum heuristic reflects consumers' belief that options in a given choice set are balanced, such that advantages on one dimension are likely to be compensated for by disadvantages on another. As a result, when an all-in-one alternative is embedded among specialized options, its attribute performance is likely to be devalued so that it matches the overall performance of these options. Similarly, the performance of specialized options on their primary attributes is bolstered and their secondary attributes are devalued so that their overall performance matches that of the all-in-one option.

Research reported in this article contributes to the decision literature by applying the notion of compensatory inferences to explain the devaluation and enhancement effects associated with evaluating specialized and all-in-one options. Building on the findings reported by Chernev and Carpenter (2001), who examine market efficiency inferences as a function of price, the research presented in this article documents a different type of compensatory inference that is not necessarily contingent on the availability of price information. Indeed, because drawing inferences about overall value is difficult in the absence of price information, the availability of price information is a necessary condition for market efficiency intuitions to occur. In contrast, the zero-sum heuristic reported in this research offers a more general decision strategy that is not necessarily contingent on the availability of pricing information. Documenting the existence of compensatory reasoning without explicitly available pricing information is an important contribution to the research on consumer decision making and choice.

It is important to note that the observed effect of adding an all-in-one option to a set comprising specialized options (and vice versa) is conceptually different from the range effects described by prior research (Janiszewski and Lichtenstein 1999; Lynch, Chakravarti, and Mitra 1991). Indeed, in the case of range effects, adding an option to the choice set changes the attribute-value scale describing choice al- 
ternatives. In contrast, in the case of the compensatory effects reported in this research, adding either a specialized or an all-in-one option does not change the scale describing choice alternatives because both the specialized and the allin-one options are described by identical attribute values (e.g., both offer "cavity prevention").

The findings reported in this research also imply that the widely used strategy of pricing specialized and all-in-one options at parity might, in fact, be suboptimal. Thus, the data show that the choice share of the all-in-one option is likely to be greater when this option is priced higher than when it is priced at parity with the specialized options. It is important to note, however, that this increase in the share of the all-in-one option when priced at a premium is not a universal rule; it is contingent on a variety of other factors, such as the price sensitivity of consumers. Thus, even though increasing the price of the all-in-one option might mitigate the devaluation effect, in cases when consumer price sensitivity is high, the overall choice share might nevertheless decrease.

An important issue raised by this research concerns identifying factors that facilitate the use of the zero-sum heuristic vis-à-vis alternative decision heuristics. In this context, three important preconditions for the zero-sum heuristic can be identified. The first one is that options in the choice set are perceived as being a part of the same subset of alternatives-for example, a part of a company's product line or a part of the assortment offered by a retailer. The second precondition is the belief that all relevant information is available and choice alternatives can be readily evaluated. Finally, the third precondition is that consumers believe that options in the choice set are balanced in terms of their overall attractiveness. Such balance might be due to the perceived market efficiency (in cases involving price and/or price promotions; Chernev and Carpenter 2001; see also Simonson, Carmon, and O'Curry 1994), technological constraints (such as the relationship between size and weight; Hauser and Shugan 1983), or commonly observed correlations (such as reliability and warranty; Broniarczyk and Alba 1994). The research presented in this article focused on documenting the specific effects associated with the use of the zero-sum heuristic and identifying some of its moderating factors, without explicitly examining the influence of all the above preconditions on the strength of the zero-sum heuristic. Identifying antecedents and the boundary conditions of the zerosum heuristic is an important and fruitful area for further research.

\section{APPENDIX}

TABLE A1

STIMULI OVERVIEW (EXPERIMENT 1)

\begin{tabular}{llll}
\hline \hline Product & \multicolumn{1}{c}{ Option A } & Option B & Option C \\
\hline Cold relief medicine & Relieves chest congestion & Clears nasal stuffiness & Relieves chest congestion and clears nasal stuffiness \\
Laundry detergent & Prevents static & Removes stains & Prevents static and removes stains \\
Shaving cream & Moisturizes & Protects & Moisturizes and protects \\
Toothpaste & Prevents cavities & Whitens teeth & Whitens teeth and prevents cavities \\
Vitamin supplements & Improve memory & Reduce stress & Improve memory and reduce stress \\
\hline
\end{tabular}

TABLE A2

STIMULI OVERVIEW (EXPERIMENT 2)

\begin{tabular}{|c|c|c|c|c|}
\hline Product & Option A & Option B & Option C & Price $^{*}$ \\
\hline Laundry detergent & Protects color & Removes stains & Protects color and removes stains & $\$ 7.99$ (\$9.99) \\
\hline Shaving cream & Moisturizes & Protects & Moisturizes and protects & $\$ 2.99(\$ 3.99)$ \\
\hline Toothpaste & Prevents cavities & Protects from tartar & Prevents cavities and protects from tartar & $\$ 1.99(\$ 2.99)$ \\
\hline Vitamin supplements & Ginseng & Ginkgo biloba & With ginseng and ginkgo biloba & $\$ 6.99(\$ 8.99)$ \\
\hline
\end{tabular}

*Premium price is given in parentheses. 


\section{REFERENCES}

Adler, Alfred (1924), The Practice and Theory of Individual Psychology, 2nd rev. ed., London: Kegan Paul.

Allison, Ralph I. and Kenneth P. Uhl (1964), "Influence of Beer Brand Identification on Taste Perception," Journal of Marketing Research, 1 (August), 36.

Baumgartner, Hans (1995), "On the Utility of Consumers' Theories in Judgments of Covariation," Journal of Consumer Research, $21,10$.

Bernoulli, Daniel (1738), "Specimen Theoriae Novae de Mensura Sortis," Commentarii Academiae Scientiarum Imperialis Petropolitanae, 175-92; English translation in Bernoulli, Daniel (1954), "Exposition of a New Theory on the Measurement of Risk," trans. Louise Sommer, Econometrica, 22, 23-36.

Bettman, James R., Deborah Roedder John, and Carol A. Scott (1986), "Covariation Assessment by Consumers," Journal of Consumer Research, 13 (December), 316-26.

Broniarczyk, Susan M. and Joseph W. Alba (1994), "The Role of Consumers' Intuitions in Inference Making," Journal of Consumer Research, 21 (December), 393-407.

Carmon, Ziv and Itamar Simonson (1998), "Price-Quality TradeOffs in Choice versus Matching: New Insights into the Prominence Effect," Journal of Consumer Psychology, 7 (4), 323-43.

Carpenter, Gregory S. and Kent Nakamoto (1989), "Consumer Preference Formation and Pioneering Advantage," Journal of Marketing Research, 26 (August), 285-98.

Chernev, Alexander and Gregory S. Carpenter (2001), "The Role of Market Efficiency Intuitions in Consumer Choice: A Case of Compensatory Inferences," Journal of Marketing Research, 38 (August), 349-61.

Chernev, Alexander and Ryan Hamilton (2007), "Too Much of a Good Thing? Option Attractiveness and Assortment Choice," working paper, Kellogg School of Management, Northwestern University, 2001 Sheridan Road, Evanston, IL 60208.

Dick, Alan, Dipankar Chakravarti, and Gabriel Biehal (1990), "Memory-Based Inferences during Consumer Choice," Journal of Consumer Research, 17 (June), 82-93.

Hardie, Bruce G. S., Eric J. Johnson, and Peter S. Fader (1993), "Modeling Loss Aversion and Reference Dependence Effects on Brand Choice," Marketing Science, 12, 17.

Hauser, John R. and Steven Shugan (1983), "Defensive Marketing Strategies," Marketing Science, 4 (Fall), 319-60.

Huber, Joel and John McCann (1982), "The Impact of Inferential Beliefs on Product Evaluations," Journal of Marketing Research, 19 (August), 324-33.

Janiszewski, Chris and Donald R. Lichtenstein (1999), “A Range Theory Account of Price Perception," Journal of Consumer Research, 25 (March), 353-68.

Janiszewski, Chris and Stijn M. J. Van Osselaer (2000), “A Connectionist Model of Brand-Quality Associations," Journal of Marketing Research, 37, 331-50.

Johnson, Eric J. and Robert J. Meyer (1984), "Compensatory Choice Models of Noncompensatory Processes: The Effect of Varying Context," Journal of Consumer Research, 11 (June), 528-41.

Johnson, Richard D. (1987), "Making Judgments When Infor- mation Is Missing: Inferences, Biases, and Framing Effects," Acta Psychologica, 66 (1), 69-82.

Johnson, Richard D. and Irwin P. Levin (1985), "More Than Meets the Eye: The Effect of Missing Information on Purchase Evaluations," Journal of Consumer Research, 12 (September), 169-77.

Kahneman, Daniel and Amos Tversky (1979), "Prospect Theory: An Analysis of Decision under Risk," Econometrica, 47 (March), 263-92.

Keeney, Ralph L. and Howard Raiffa (1976), Decisions with Multiple Objectives : Preferences and Value Tradeoffs. New York: Wiley.

Kivetz, Ran and Itamar Simonson (2003), "The Idiosyncratic Fit Heuristic: Effort Advantage as a Determinant of Consumer Response to Loyalty Programs," Journal of Marketing Research, 40 (February), 454-67.

Lichtenstein, Donald R. and Scot Burton (1989), "The Relationship between Perceived and Objective Price-Quality," Journal of Marketing Research, 26 (November), 429-43.

Lynch, John G., Dipankar Chakravarti, and Anusree Mitra (1991), "Contrast Effects in Consumer Judgments: Changes in Mental Representations or in the Anchoring of Rating Scales?" Journal of Consumer Research, 18 (December), 284-97.

Nowlis, Stephen M. and Itamar Simonson (1996), "The Effect of New Product Features on Brand Choice," Journal of Marketing Research, 33 (February), 36-46.

Payne, John W., James R. Bettman, and Eric J. Johnson (1993), The Adaptive Decision Maker. New York: Cambridge University Press.

Prelec, Drazen, Birger Wernerfelt, and Florian Zettelmeyer (1997), "The Role of Inference in Context Effects: Inferring What You Want from What Is Available," Journal of Consumer Research, 24 (June), 118-25.

Raghubir, Priya and Kim Corfman (1999), "When Do Price Promotions Affect Pretrial Brand Evaluations?" Journal of Marketing Research, 36, 211-22.

Rao, Akshay R. and Kent B. Monroe (1989), "The Effect of Price, Brand Name, and Store Name on Buyers' Perceptions of Product Quality: An Integrative Review," Journal of Marketing Research, 26, 351-57.

Shiv, Baba, Ziv Carmon, and Dan Ariely (2005), "Placebo Effects of Marketing Actions: Consumers May Get What They Pay For," Journal of Marketing Research, 42 (November), 383-93.

Simonson, Itamar (1989), "Choice Based on Reasons: The Case of Attraction and Compromise Effects," Journal of Consumer Research, 16 (September), 158-74.

Simonson, Itamar, Ziv Carmon, and Suzanne O’Curry (1994), "Experimental Evidence on the Negative Effect of Product Features and Sales Promotions on Brand Choice," Marketing Science, 13 (1), 23-40.

Simonson, Itamar, Stephen Nowlis, and Katherine Lemon (1993), "The Effect of Local Consideration Sets on Global Choice between Lower Price and Higher Quality," Marketing Science, 12 (4), 357-77.

Simonson, Itamar and Amos Tversky (1992), "Choice in Context: Tradeoff Contrast and Extremeness Aversion," Journal of Marketing Research, 29 (August), 281-95.

Torgerson, Warren S. (1958), Theory and Methods of Scaling. Oxford: Wiley. 
Tversky, Amos (1972), "Elimination by Aspects: A Theory of Choice," Psychological Review, 79 (October), 281-99.

Tversky, Amos and Daniel Kahneman (1991), "Loss Aversion in Riskless Choice: A Reference-Dependent Model," Quarterly Journal of Economics, 106 (November), 1039-61.

Von Neumann, John and Oskar Morgenstern (1953), Theory of Games and Economic Behavior, 3rd ed., New York: Wiley.

Wernerfelt, Birger (1988), "Umbrella Branding as a Signal of New
Product Quality: An Example of Signalling by Posting a Bond," Rand Journal of Economics, 19, 9.

(1995), "A Rational Reconstruction of the Compromise Effect: Using Market Data to Infer Utilities," Journal of Consumer Research, 21 (March), 627-33.

Winer, B. J., Donald R. Brown, and Kenneth M. Michels (1991), Statistical Principles in Experimental Design, 3rd ed., New York: McGraw-Hill. 